\title{
Advancing carbon, energy materials: Mildred S. Dresselhaus talks about her work
}

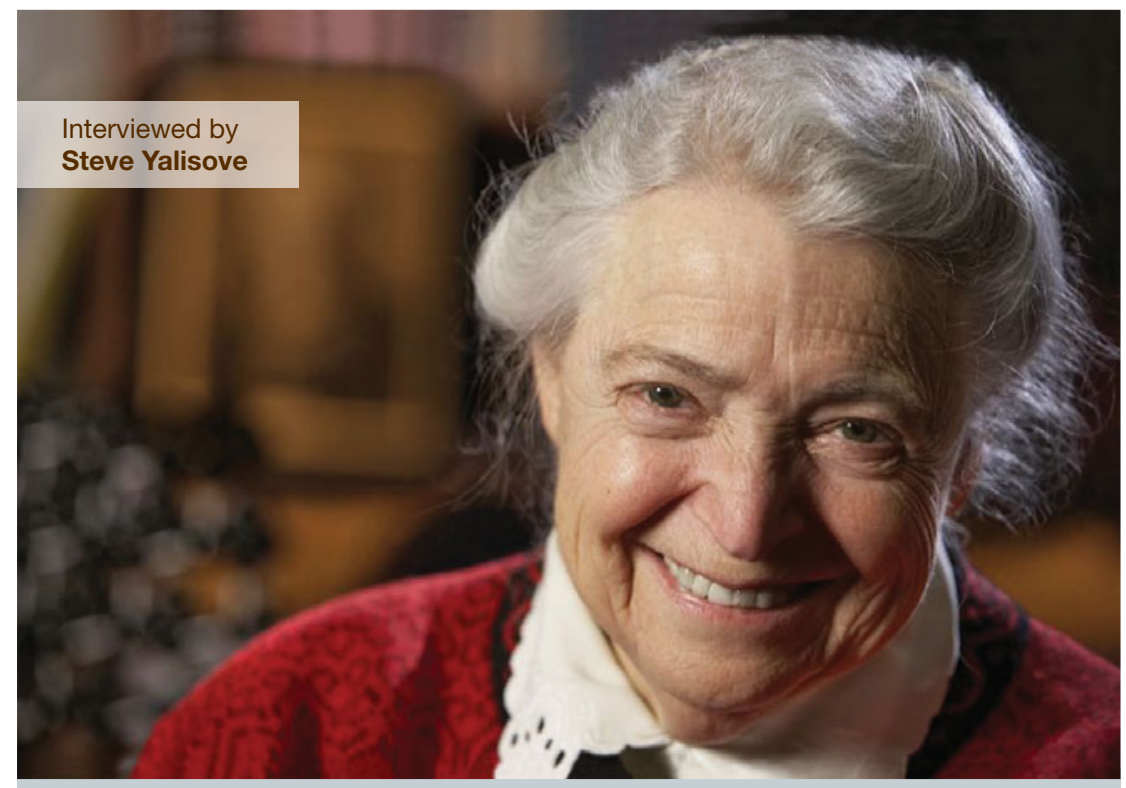

Mildred S. Dresselhaus has been leading a rich career in materials research pursuing, more often than not, unpopular topics such as the study of carbon nanostructures in the 1960s. Her career has taken her through research laboratories, government service, and academia where she is now Emerita Institute Professor at the Massachusetts Institute of Technology (MIT). During a discussion about inspiring students, Dresselhaus said, "Tell the class some of the stories behind the research. It shows them that they can contribute something. Otherwise, it's just stuff they're having a hard time understanding." Throughout the interview, Dresselhaus showed how materials research was advanced at the workplace and through chance connections at conferences.

\section{MRS BULLETIN: What drew you} to the study of graphene? MILDRED S. DRESSELHAUS: At my first job as an independent researcher at MIT Lincoln Laboratory, they told me I could work on most anything, but not what I knew something about. That is actually very good advice to a young person starting a career because you bring new ideas to the field.

The concept of graphene came along in 1947, but nobody paid much attention to it. I was fascinated because it had a linear $\mathrm{E}$ versus $\mathrm{K}$ while everything else that people were working on at that time had a quadratic dispersion relationship. I wondered why this was and what was so special about it. That was my fascination. The people at Lincoln Lab were a little surprised, but they put up with me because I produced a number of papers that they thought were sort of interesting.

In the very first years of what I was publishing, essentially nobody else was publishing in this area with the exception of Joel McClure, who was a classmate of mine two years ahead of me at the University of Chicago. He was a theorist. After graduation he worked for a number of years for Union Carbide. Probably less than 10 people internationally worked in this field. We knew one another through the literature, but there was no conference to bring us together at that time.

We didn't know how to study graphene because nobody knew how to make a single layer. We were busy trying to understand graphite as a bulk material, the very simplest form of a layered material. We wrote many papers on many aspects measuring any conceivable property we could think of for graphite, and with the combination of these experiments, we were able to help Joel McClure's theory.

\section{What caught your attention in carbon nanostructures?}

The community had little interest in carbon and carbon nanostructures. Everybody was pursuing silicon, germanium, and III-V compounds. I wanted to do something different, and I thought what I was doing was more interesting because it had a uniqueness factor.

A carbon nanotube is just a graphene sheet that's rolled up seamlessly and this happens in nature; carbon nanotubes are found in mineral deposits around the planet. Something that's a cylinder, which is like a one-dimensional system, has a different science, different physics, different materials science, different properties, and it is clear to me that those properties might be used for some applications in preference to the applications of the planar material, which is called "graphene."

Also, I chose carbon because at that time, in the 1960s, I had a very young family. I had one child, a second one on the way, and I needed time because sometimes in the morning I couldn't make the eight o'clock time that we were supposed to arrive at work. Lincoln Lab was very unhappy with me because they expected me there every morning on time and 8:15 was not good enough, so this was not easy. There was at least one other woman who had the same problem as me, and approximately a thousand men on the technical staff who didn't understand 
very well that women in science have special difficulties in meeting very stringent time regulations. Carbon research was not as competitive, so getting results one day later did not matter so much. The semiconductor area, which was popular, was very competitive, so timing was critical.

\section{How did conferences advance the study of carbon nanotubes?}

The first conference was held in

1977, at a chateau in France called La Napoule. Different folks in this field of study met for the first time. So, for example, Hanns Peter Boehm, who made a single-layer graphene in the 1961-1962 time frame, was at this conference. Even though he started to work in this area and published a few papers, he never followed up on this because people were paying attention to other things that he was doing, such as his work on graphite intercalation compounds.

Carbon nanotubes were discovered in Russia in the 1950s, but the papers were in Russian and not known in the West. Carbon nanotubes were independently discovered in the early 1970s by a number of groups in different countries. The earliest serious work was in Japan in the group by Morinobu Endo in Shinshu University, which was not a mainstream university at that time, and so people didn't know about that work internationally. He was working with carbon fibers most of the time.

In 1977, there was also a conference in Japan at a resort far from the centers where Western people journeyed at that time. Ryogo Kubo, who is a very famous Japanese theorist, asked Endo a historic question: Would it be possible to make a carbon fiber that was just one layer thick? And that was the beginning of the concept of the single-walled nanotube for me.

I met Endo in 1980, at the Second International Conference on Intercalation Compounds. I was very much taken with carbon fibers because they seemed like the perfect medium to explore transport studies in carbon-

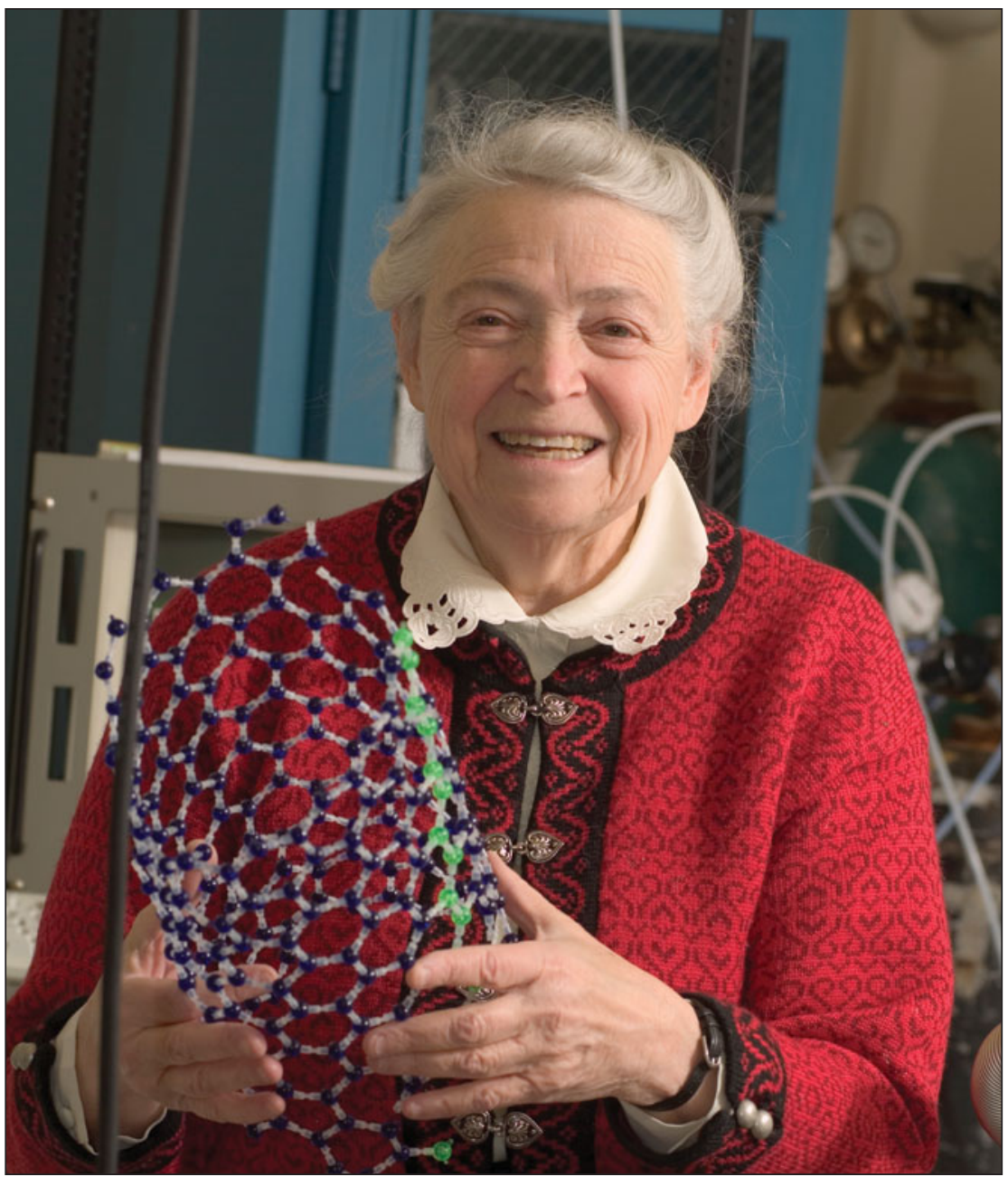

based systems. I teamed up with Endo and we worked on transport measurements and then intercalation and all kinds of things for the next $30+$ years.

\section{What revolutionized this field?}

In 1990, we had a public discussion with Rick Smalley at a conference that was called by the US Department of Defense. Smalley was invited because he had discovered fullerenes and I was invited because I knew something about carbon fibers. The connection between carbon nanotubes and fullerenes was not apparent at the time, so they invited about 20 or 30 people from the two communities.

You could think of a carbon nanotube as a cylinder, you could think of fullerene as a ball, and if you elongate the ball then you can imagine that you could transform the ball into a tube. $\mathrm{C}_{60}$ is sort of a spherical kind of shape, so you can elongate to $\mathrm{C}_{70}$, $\mathrm{C}_{80}, \mathrm{C}_{90}, \mathrm{C}_{100}$, and just keep elongating it and eventually you get a cylinder.

That was the connection that we made at that conference.

In 1991, [Matsutaka] Fujita and [Riichiro] Saito, two young physicists who had faculty positions in Japan, came to MIT on sabbatical leave. They didn't know each other and somehow both approached me. I gave these two theorists the same project to work on together, because one was more on the geometrical side and the other one was more analytic. Very soon they came up with the idea that a carbon nanotube could either be metallic or semiconducting. When we published this very first paper back in 1992, people didn't believe that any single material could be either semiconducting or metallic, depending on how you oriented the hexagon forming the six fundamental 

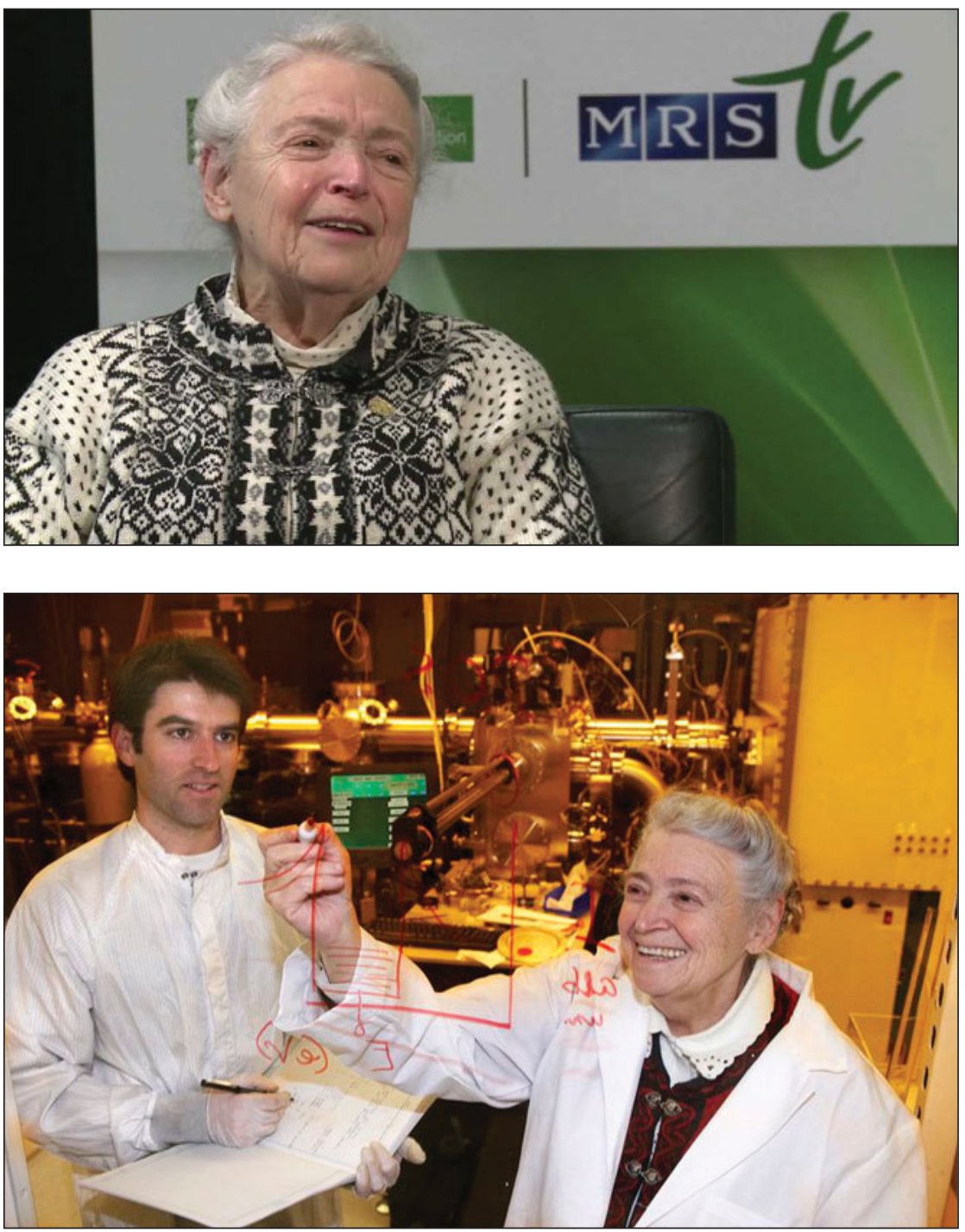

atoms in the unit cell with respect to the axis of the cylinder that was formed when you made a nanotube. So this was something that people just couldn't comprehend, and it took six years before many of our colleagues believed that our paper was correct.

\section{How did you become involved in hydrogen?}

My entry into the field of hydrogen study came as a great surprise to me. Somebody from the government approached me saying that the president made some comments about hydrogen and its value in the energy program. I had been president of AAAS [American Association for the Advancement of Science], which may be how I came to their attention.
When I was president of AAAS, I invited President Clinton to give the keynote speech. I told him that President Truman had been important in promoting science, which was very valuable for the future of the country. Clinton did come to celebrate the 150th anniversary of the AAAS and became interested in science from that time onwards. I worked for him during his second term, where I was head of the Office of Science for the Department of Energy.

I was then later called by George W. Bush, who introduced the concept of the Hydrogen Initiative. Hydrogen was not at all popular in the Department of Energy at that time. I knew little about the Hydrogen Initiative myself, so I formed a small committee with people I knew through AAAS who could help me on a study for President Bush's proposal. George Crabtree, who knew more than I did about hydrogen, was on that committee and we started working closely as a result of that particular challenge. I think my experience in AAAS gave me the background to understand how to interact with government, and how civilians could provide information of value to the government on important scientific issues. Our committee wrote a report in that context and it became the model for at least a dozen later reports giving advice to the government.

\section{What defines a good mentor?}

Mentoring is about listening to people, helping them go over what the issues are and how to clarify ways to deal with any problems that may arise. It's not about making decisions for them but having them make the decisions. Helping people find their own career paths is a big part of mentoring. It has to be their choice because they're going to have to face the consequences. I think having four children made me a good mentor. As a parent you get to know young people as they mature and grow up and to also learn about some of the difficulties they face. When you mentor, you want them to feel more enabled to deal with the problems than when they entered the room.

What can you say about diversity? Diversity and inclusion of women and underrepresented minorities in science should not affect the way education is handled or research is carried out. So diversity should not be a problem, but rather an opportunity to involve a large talent pool. In fact, it should be an enrichment because people coming with different backgrounds may be able to deal with one another somewhat diversely too, which might be a benefit. And in science, diversity is a benefit. Being able to look at a given issue or a given phenomenon from different standpoints provides a richness of the scientific method. 


\section{$56^{\text {th }}$ Electronic Materials Conference}

\section{June 25-27, 2014 // University of California, Santa Barbara // Santa Barbara, CA}

\section{MARK YOUR CALENDAR}

The 56th Electronic Materials Conference (EMC 2014) is the premier annual forum on the preparation and characterization of electronic materials. Held June 25-27 at the University of California, Santa Barbara, this year's Conference immediately follows the Device Research Conference and will feature a plenary session, parallel topical sessions, a student best presentation competition, a poster session and an industrial exhibition. Mark your calendar today and plan to attend!

\section{SCIENTIFIC PROGRAM}

The three-day Conference will feature oral and poster presentations covering:

\section{ENABLING TECHNOLOGIES}

- Compound Semiconductor Growth on Si Substrates

and Si-Based Heterojunctions

- Contacts to Semiconductor Epilayers, Nanowires,

Nanotubes and Organic Films

- Dilute Nitride Semiconductors

- Embedded Nanoparticles and Rare-Earth-Materials

in III-V Semiconductors

- Epitaxial Materials and Devices

- Materials Integration: Wafer Bonding and Engineered Substrates

- Metamaterials and Materials for THz, Plasmonics, and Polaritons

- Nano-Magnetic, Magnetic Memory and Spintronic Materials

- Narrow Bandgap Materials and Devices

- Optomechanics

- Oxide Thin Films: Alternative Dielectrics, Epitaxial Oxides,

Multifunctional Oxides, Superlattices, and Metal Gates

- Semiconductor: Oxidation, Passivation, and Etching

\section{ENERGY CONVERSION AND STORAGE MATERIALS}

- Electrochemical Energy Storage and Conversion

- Highly Mismatched Dilute Alloys

- Photovoltaics: Organic and Hybrid

- Solar Cell Materials and Devices

- Thermoelectrics

\section{NANOSCALE SCIENCE AND TECHNOLOGY IN MATERIALS}

- Carbon Nanotubes: Growth, Processing, Characterization and Devices

- Graphene, BN, $\mathrm{MoS}_{2}$ and Other 2D Materials and Devices

- Low-Dimensional Structures: Quantum Dots, Wires and Wells

- Nanoscale Characterization: Scanning Probes, Electron Microscopy and Other Techniques

- Nanowires: Growth, Processing, Characterization and Devices

- Topological Insulators

\section{ORGANIC MATERIALS AND THIN FILM TECHNOLOGY}

- Biomaterials and Interfaces

- Flexible, Printed, and/or Dissolvable Thin Film Electronics

- Molecular Electronics and OLEDs: Devices, Materials and Sensors

- Organic Thin Film and Crystalline Transistors:

Devices, Materials and Processing

- Transparent Conductors

\section{WIDE BANDGAP MATERIALS}

- Indium Nitride: Growth, Processing, Characterization, Theory and Devices - Oxide Semiconductors: Growth, Doping, Defects,

Nanostructures and Devices

- Point Defects, Doping and Extended Defects

- Silicon Carbide: Growth, Processing, Characterization, Theory and Devices

\section{CONFERENCE VENUE}

The University of California, Santa Barbara is a world-renowned educational institution, with a faculty of five Nobel Laureates and many elected members or fellows of the American Academy of Arts and Sciences, the National Academy of Sciences, the National Academy of Engineering, and the American Association for the Advancement of Science. Situated on a beautiful coastal bluff, the University will provide a stunning backdrop to EMC 2014. Santa Barbara is less than 100 miles from hyper-metropolitan Los Angeles but differs vastly from its huge neighbor to the south. A mild climate, lush natural beaches, highly rated food and wine and a wide variety of shopping make the "Riviera of the West" a perfect vacation and Conference destination. supported by a grant from the TMS Foundation.

Conference Organizer

Andrew Allerman Sandia National Laboratories

Program Organizer

Jamie Phillips University of Michigan

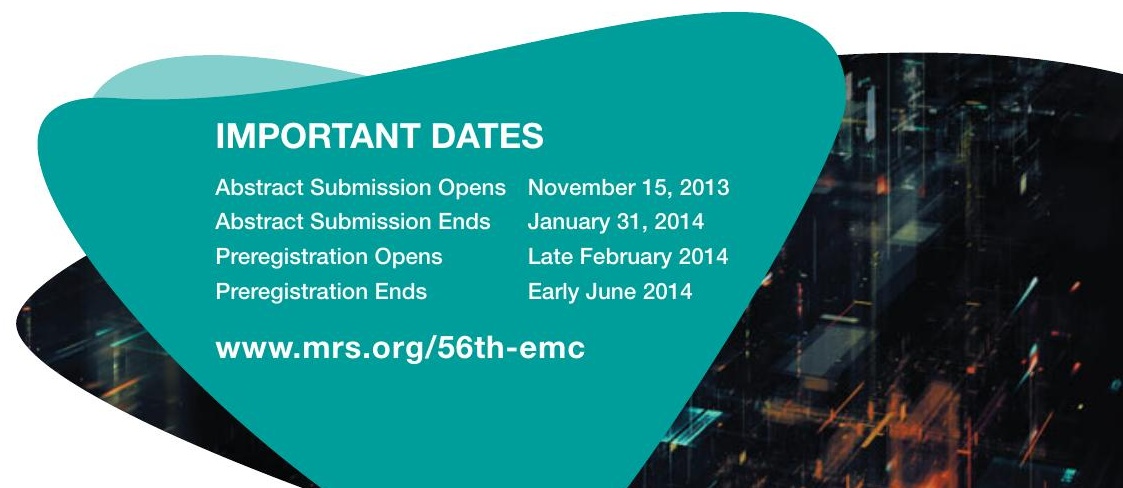




\section{THANKSI

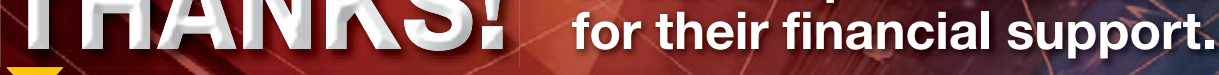

1-Material, Inc.

Abengoa Research

Accelrys, Inc.

Agilent Technologies

Air Liquide

AIST-NT, Inc.

AIXTRON SE

American Institute of Physics

American Scientific Publishers

Anfatec Instruments AG

Angstrom Engineering Inc.

Applied Diamond, Inc.

Argonne National Laboratory

ASM International

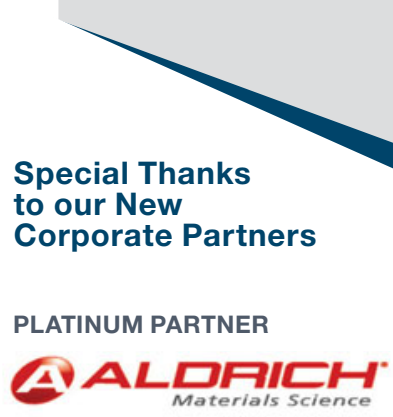

www.sigma-aldrich.com/matsci

SILVER PARTNERS

CRC Press

Taylor \& Francis Group

www.crcpress.com

\section{눈 LakeShore}

www.lakeshore.com

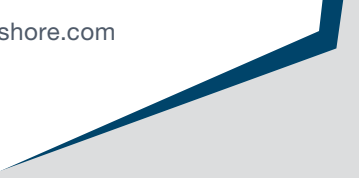

Asylum Research, an Oxford Instruments Company

Baruch Future Ventures, LLC

Beijing Mikrouna Mechatronics Technology Company, Ltd.

Biolin Scientific, Inc.

Biomatik Corporation

Bluestone Global Tech, Inc.

Brookhaven National Laboratory

Bruker Nano Surfaces

Bruker Optics Inc.

Cabot Microelectronics Corporation

Carl Zeiss Microscopy, LLC
CEOS GmbH

Cline Innovations, LLC

Corning Inc.

CP Kelco

CrysTec GmbH

Delong America Inc.

Digital Surf SARL

Dow Chemical Company

Dr. Eberl MBE-Komponenten $\mathrm{GmbH}$

DuPont Central Research and Development

École Polytechnique Fédérale de Lausanne

Element Six

EMD Millipore Corporation

FCT Systeme GmbH

FEI Company

Fischione Instruments, Inc.

Fisher Scientific

Forschungszentrum Julich $\mathrm{GmbH}$

Fraunhofer USA CCL

Fuji Electronic Industrial Co., Ltd.

Fujimi Corporation

GE Global Research

Gelest, Inc.

Genzyme Corporation

GMZ Energy Inc.

Graphenea Nanomaterials

Helmholtz-Zentrum Berlin

Helmholtz-Zentrum Dresden-

Rossendorf

Hitachi High Technologies

America, Inc.

Honda R\&D Co., Ltd.

Hysitron, Inc.

International Centre for Diffraction Data (ICDD)

iPen Inc.

iTRIX Corporation

Janis Research Company, LLC

JEOL USA, Inc.

Joanneum Research

Forschungsgesellschaft $\mathrm{mbH}$

Karlsruhe Institute for Technology

Lawrence Berkeley National Laboratory

Lawrence Livermore National Laboratory

Los Alamos National Laboratory

M.Braun, Inc.

Magnolia Solar, Inc.

Mantis Deposition Ltd.

Materion Corporation

Max Planck Institute of Colloids and Interfaces

MDC Vacuum Products, LLC

MEMC Electronic Materials, Inc.

Micron Technology Foundation Inc.

NanoMagnetics Instruments Ltd.

Nanomechanics, Inc.
NanoScan Ltd.

NanoWorld AG

National Electrostatics Corporation

National Institute of Standards

and Technology

National Physical Laboratory

National Renewable Energy Laboratory

NBM Design, Inc.

NION

Nissan ARC, Ltd.

Novellus Systems, Inc.

Oak Ridge National Laboratory

Oxford Instruments

Park Systems Inc.

Photovoltaic Power Generation

Technology Research Association

Physical Electronics

Picosun USA, LLC

planarTECH

PX Services SA

Quantum Design, Inc.

Research and PVD Materials Corporation

Rocky Mountain Vacuum Tech, Inc.

Royal Society of Chemistry

Royal Society Publishing

SAMCO Inc.

Sandia National Laboratories

SBA Materials, Inc.

Schrödinger

Seki Diamond Systems

SPECS Surface Nano Analysis

SPI Supplies/Structure Probe, Inc.

Springer

STAIB Instruments, Inc.

SuperPower Inc.

SURFACE Systems \& Technology

$\mathrm{GmbH} \& \mathrm{Co}$. KG

Teleflex Medical OEM

Thermal Technology LLC

Thermo Fisher Scientific

Tokyo Electron America, Inc.

United Technologies Research Center

VWR International, LLC

Wiley-VCH Verlag GmbH \& Co. KGaA

WITec Instruments Corp.

Zygo Corporation

For more information contact:

Mary E. Kaufold

Manager, Advertising \& Exhibits

Materials Research Society

Tel: 724-779-2755

Cell: 724-996-5683

kaufold@mrs.org 